\title{
Autoimmune polyendocrine syndrome type II: After adrenal crisis
}

\author{
Nuno Zarcos Palma*1, Mariana da Cruz ${ }^{1}$, Lígia Rodrigues dos Santos ${ }^{1}$, Margarida Cruz ${ }^{1}$, Filipe Cunha ${ }^{2}$, Vítor \\ Fagundes $^{1}$, Lindora Pires ${ }^{1}$, Mari Mesquita ${ }^{1}$ \\ ${ }^{1}$ Serviço de Medicina Interna, Centro Hospitalar Tâmega e Sousa, E.P.E., Penafiel, Portugal \\ ${ }^{2}$ Unidade de Endocrinologia, Centro Hospitalar Tâmega e Sousa, E.P.E., Penafiel, Portugal
}

Received: October 22, 2019

Accepted: May 25, 2020

Online Published: June 7, 2020

DOI: $10.5430 /$ crim.v7n2p3

URL: https://doi.org/10.5430/crim.v7n2p3

\begin{abstract}
Autoimmune Polyendocrine Syndromes (APS) are rare autoimmune endocrinopathies, characterized by the association of two or more organ-specific disorders. Type II Autoimmune Polyendocrine Syndromes (APS II) comprises the association of Addison's disease with thyroid autoimmune disease and/or type 1 diabetes mellitus. Although the classic presentation is symptomatic hypotension, it can manifest as an adrenal crisis - a life-threatening condition. We report a case of a 41-year-old woman with prolonged asthenia, cutaneous hyperpigmentation and symptomatic hypotension refractory to intravenous fluids. APS II was diagnosed with a presentation of an Addisonian crisis, resolved after the onset of hydrocortisone.
\end{abstract}

Key Words: Adrenal crisis, Addison's disease, Autoimmune Polyendocrine Syndrome, Schmidt's syndrome, Carpenter's syndrome

\section{INTRODUCTION}

Autoimmune Polyendocrine Syndromes (APS) comprise clinical conditions with functional impairment of multiple endocrine glands caused by loss of immune tolerance. APS is characterized by the coexistence of at least two glandular autoimmune diseases. ${ }^{[1]}$ There are 4 types of APS (I, II, III, IV). Although, in the literature some experts consider only type I and II, with the APS-II encompassing types III and IV ${ }^{[2]}$ APS-I often appears early in life, typically in infants with persistent candid infection of the skin and mucous membranes. APS-I is caused by a mutation in an autoimmune-suppressor gene (AIRE). Two of the following conditions must be present: mucocutaneous candidiasis, hypoparathyroidism, or Addison's disease. ${ }^{[3]}$ The APS-II has a low prevalence of 1:1000, with a higher in women and typical onset in adulthood. APS-II comprises the association of Addison's disease (primary adrenal insufficiency) with thyroid autoimmune disease and/or type 1 diabetes mellitus. Moreover, conditions such as alopecia, vitiligo, celiac disease, and autoimmune gastritis with vitamin B12 deficiency may also manifest in this syndrome. Combination of Addison's disease and chronic lymphocytic thyroiditis was first described in two patients by Schmidt's in 1926, hence the eponymous Schmidt's syndrome. The triad Addison's disease, chronic lymphocytic thyroiditis and type 1 diabetes is also known as Carpenter's syndrome. ${ }^{[1,2,4]}$ The APS-III refers to thyroid autoimmunity with yet another autoimmune disorder except Addison's disease or type 1 diabetes. The APS-IV refers to two or more other organ-specific autoimmune diseases. The treatment of these syndromes is directed

\footnotetext{
* Correspondence: Nuno Zarcos Palma; Email: nzarcospalma@gmail.com; Address: Serviço de Medicina Interna, Centro Hospitalar Tâmega e Sousa, E.P.E., Penafiel, Portugal. 
to the specific disorders. ${ }^{[2,4]}$

Adrenal insufficiency is a consequence of deficient production or action of glucocorticoids. It may result from, either primary adrenal failure or secondary adrenal disease due to impairment of the hypothalamic-pituitary axis. The cardinal clinical symptoms of adrenocortical insufficiency, as first described by Thomas Addison in 1855, include: (i) weakness, (ii) fatigue, (iii) anorexia, and (iv) abdominal pain. In combination with primary adrenal failure may occur orthostatic hypotension, salt craving, and characteristic hyperpigmentation of the skin. Adrenal crisis is an acute syndrome that constitutes a medical emergency as it can result in a severe hypotensive. ${ }^{[6,7]}$

We report a case of a woman who presented with chronic fatigue culminating in an Addisonian crisis. In addition to Addison's disease, which is a rare disorder, thyroiditis and risk for type 1 diabetes mellitus were diagnosed, thus fulfilling the criteria for APS II.

\section{Case presentation}

A 41-year-old woman with a history of chronic back pain from herniated discs, complained of progressive fatigue and dizziness in the previous 6 months. The patient also reported a dark skin tan that she associated with prolonged sun exposure. Her past medical history as well as her family history had no other relevant clinical information.

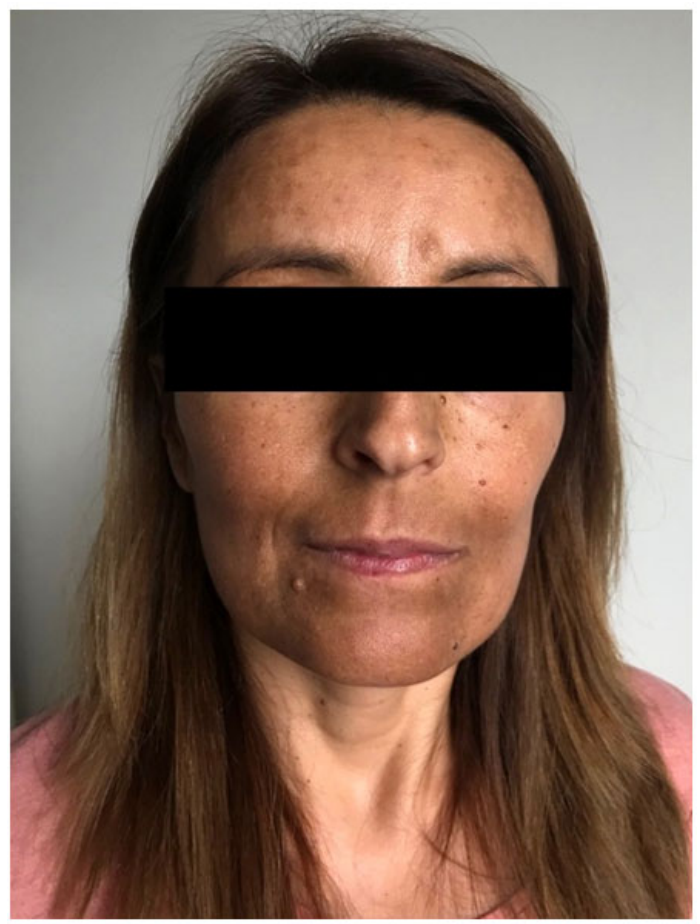

Figure 1. Diffuse skin hyperpigmentation, with peri-buccal predominance

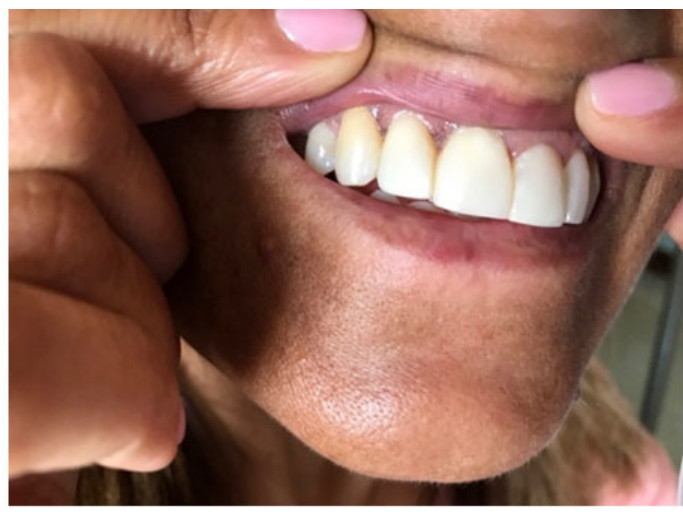

Figure 2. Pigmented gum lesions caused by a hormone imbalance

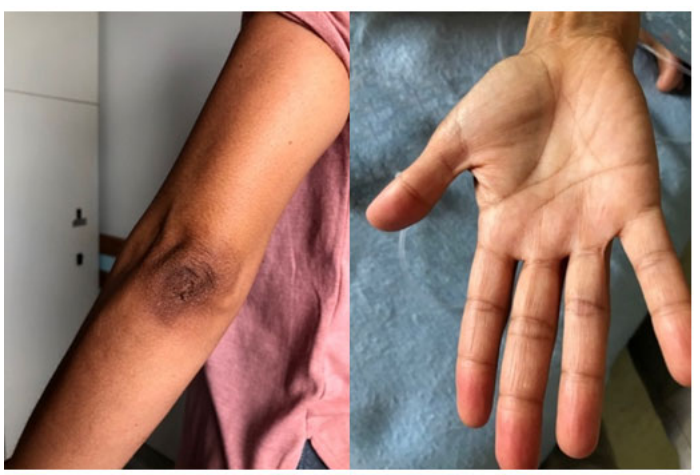

Figure 3. Increased pigmentation, more exuberant in the skin folds (left). Increased pigmentation of the palmar creases and wrists (right).

The patient was admitted to the hospital emergency department (ED) due to chills, nausea, vomiting, abdominal pain, generalized malaise and fever $\left(38.7^{\circ} \mathrm{C}\right)$. She had no obvious focus of infection. Objectively, she was prostrated, presented shivering, low-amplitude and symmetrical peripheral pulses, blood pressure was $67 / 54 \mathrm{mmHg}$ (median of 3 measures), heart rate was 104/minute, respiratory rate 10/minute, generalized cutaneous hyperpigmentation (see Figures 1-3), more exuberant in the skin folds, peri-buccal, pigmented lesions in the gums. No alterations in cardiopulmonary auscultation or abdominal examination were detected. After fluid resuscitation with isotonic saline bolus $(2,000 \mathrm{ml})$, her blood pressure maintained low values. The possibility of adrenal crisis was considered and a bolus of $100 \mathrm{mg}$ of hydrocortisone was administered, in addition to maintaining fluid therapy with isotonic saline solution. Afterwards, the patient started to improve under dexamethasone and isotonic saline fluids.

Laboratory tests were performed in 24 hours as seen in Table 1. After stabilization, she performed an ACTH stimulation test that confirmed the diagnosis. Morning blood cortisol level was $<0.5 \mu \mathrm{g} / \mathrm{dl}$, ACHT level was $>1,250 \mathrm{pg} / \mathrm{ml}$ 
and a blood cortisol level 60 minutes after $250 \mu \mathrm{g}$ tetracosactide was $1.26 \mu \mathrm{g} / \mathrm{dl}$. The abdominal computed tomography scan showed adrenal glands of reduced dimensions, and no nodules nor masses, suggesting autoimmune etiology. Antibodies (ab) against 21-hydroxylase were positive, suggesting autoimmune adrenalitis. Direct renin concentration was $59.2 \mathrm{pg} / \mathrm{ml}$ and aldosterone $<7 \mathrm{pg} / \mathrm{ml}$, denoting adrenal cortex involvement. TSH was $1.49 \mu \mathrm{UI} / \mathrm{ml}$, free T4 $0.8 \mathrm{ng} / \mathrm{dl}$, thyroid peroxidase antibodies (anti-TPO) and antithyroglobulin were positive, compatible with autoimmune thyroiditis. Anti-glutamic acid decarboxylase 65 antibodies (GAD 65) was $704 \mathrm{IU} / \mathrm{ml}$, but fasting glycemic and glycosylated hemoglobin were normal $(98 \mathrm{mg} / \mathrm{dl}$ and $\mathrm{HbA} 1 \mathrm{c}$ $5.1 \%)$.

The diagnosis of APS II (Schmidt's syndrome) was made after confirmation of autoimmune adrenalitis, causing primary adrenal insufficiency (Addison's disease) together with autoimmune thyroiditis.

The patient was discharged with hydrocortisone $10 \mathrm{mg}$ in the morning, $5 \mathrm{mg}$ at lunch, $5 \mathrm{mg}$ at $5 \mathrm{pm}$ and fludrocortisone $0.1 \mathrm{mg}$. At the follow-up consultation, two weeks after hospital discharge, she had normal blood pressure and denied any symptoms. There were no intercurrences, including hospitalization.

Table 1. Exam results

\begin{tabular}{|c|c|c|}
\hline \multicolumn{3}{|c|}{ Laboratory Tests } \\
\hline Parameter & Result & Reference \\
\hline Hemoglobin & 12.8 & $12-15 \mathrm{~g} / \mathrm{dl}$ \\
\hline Leukocytes & 3.18 & $4,5-1110^{3} / \mu \mathrm{l}$ \\
\hline Platelets & 154 & $150-40010^{3} / \mu 1$ \\
\hline Creatinine & 0.8 & $<1.1 \mathrm{mg} / \mathrm{dl}$ \\
\hline $\mathrm{Na}^{+}$ & 131 & $136-144 \mathrm{mmol} / \mathrm{L}$ \\
\hline $\mathrm{K}^{+}$ & 4.4 & $3.5-5.1 \mathrm{mmol} / \mathrm{L}$ \\
\hline $\mathrm{Cl}^{-}$ & 101 & $101-111 \mathrm{mmol} / \mathrm{L}$ \\
\hline Cortisol 8h & $<0.5$ & $6.7-22.6 \mu \mathrm{g} / \mathrm{dl}$ \\
\hline ACTH $8 \mathrm{~h}$ & $>1250$ & $<46 \mathrm{pg} / \mathrm{ml}$ \\
\hline $\begin{array}{l}\text { Cortisol } 1 \mathrm{~h} \text { after } 250 \mu \mathrm{g} \\
\text { tetracosactide }\end{array}$ & 1,26 & $\mu \mathrm{g} / \mathrm{dl}$ \\
\hline Anti-21-hydroxylase $\mathrm{Ab}$ & $1 / 320$ & $<1 / 5$ \\
\hline Direct renin concentration & 59.2 & $1.1-20.2 \mathrm{pg} / \mathrm{ml}$ \\
\hline B12 vitamin & 412 & $180-914 \mathrm{pg} / \mathrm{ml}$ \\
\hline Aldosterone & $<7$ & $42-202 \mathrm{pg} / \mathrm{ml}$ \\
\hline TSH & 1.49 & $0.38-5.33 \mu \mathrm{UI} / \mathrm{ml}$ \\
\hline FT4 & 0.8 & $0.54-1.24 \mathrm{ng} / \mathrm{dl}$ \\
\hline Anti-Thyroperoxidase Ab. & 119.5 & $<9 \mathrm{IU} / \mathrm{ml}$ \\
\hline Anti-Thyroglobulin Ab. & 97 & $<4 \mathrm{IU} / \mathrm{ml}$ \\
\hline Anti-GAD 65 antibodies & 704 & $<5 \mathrm{IU} / \mathrm{ml}$ \\
\hline Fasting Glycemia & 98 & $<110 \mathrm{mg} / \mathrm{dl}$ \\
\hline $\mathrm{HbA1c}$ & 5.1 & $<6.5 \%$ \\
\hline
\end{tabular}

Published by Sciedu Press

\section{Discussion}

Addison's disease is a rare disorder, variable in etiology, and its diagnosis is only possible with a high clinical suspicion. ${ }^{[6,7]}$ Hypotension is a common manifestation of multiple disorders, being also the classic presentation of adrenal insufficiency. The association between severe hypotension with clouded sensorium, fever, abdominal and muscle pain, as described in this case, suggests an Addisonian crisis (adrenal crisis), a life-threatening condition. ${ }^{[6,7]}$ The final diagnosis was only possible through thorough anamnesis and physical examination, identifying, respectively, chronic fatigue and skin hyperpigmentation, which is a phenotypic characteristic.

Regarding the etiology, on the one hand, in developed countries the most frequent etiology is due to autoimmune destruction of the adrenal glands. On the other hand, in developing countries the most frequent etiology is due to infectious causes, such as tuberculous adrenalitis. In addition, there are other causes such as hemorrhage, inhibition of cortisolsynthesis enzyme and activation of cortisol metabolism, but its prevalence is lower. In this case, acute infection as the cause of the adrenal crisis and chronic infections as the cause of adrenalitis were ruled out based on the absence of systemic inflammatory response syndrome, sterile blood and urine cultures as well as negative interferon gamma release assay (IGRA). Other less common causes were excluded due to the clinical history. ${ }^{[5]}$

After the diagnosis of autoimmune adrenalitis, we should be aware of the high probability of the presence or risk of developing other endocrine diseases due to autoimmune predisposition. ${ }^{[4]}$

The authors identified in this patient an euthyroid thyroiditis and risk for type 1 diabetes. Therefore, knowledge of the frequent association between Addison's disease and other autoimmune diseases allows for early diagnosis and prevention of ad initium complications. ${ }^{[5]}$ Although the patient had no criteria for the diagnosis of diabetes, she is at risk of developing the disease. Despite the possible prediction of type $1 \mathrm{~A}$ diabetes, the preventive therapies studied so far have not altered the progression of the disease. ${ }^{[4,8]}$

\section{Conclusion}

The adrenal insufficiency sometimes manifests itself as a medical emergency, making the rapid diagnosis imperative for corticosteroid treatment. The confirmation of autoimmune adrenalitis was performed and towards its diagnosis there is a high probability that other organ-specific autoimmune diseases are present or may develop, and thus doctors should be aware. It is important to educate the patient towards recognition of first signs of complement disorders 
contributing to prevention of illness and even death. The CONFLICTS OF INTEREST DisCLOSURE

management of APS consists of hormone-replacement ther- The authors have declared no conflicts of interest.

apy as needed, prevention and treatment of complications.

\section{REFERENCES}

[1] Eisenbarth GS, Gottlieb PA. Autoimmune polyendocrine syndromes. N Engl J Med. 2004; 350: 2068-2079. PMid:15141045. https: //doi.org/10.1056/NEJMra030158

[2] Better C, Lazzarotto F, Presotto F. Autoimmune polyglandular syndrome type 2: the tip of an iceberg? Clin Exp Immunol. 2004; 137 225-233. PMid:15270837. https://doi.org/10.1111/j.1365 $-2249.2004 .02561 . \mathrm{x}$

[3] Schmidt MB. Eine biglandulare Erkrankung (Nebennieren und Schilddrüse) bei Morbus Addisonii. Verh Dtsch Ges Pathol. 1926; 21: $212-221$

[4] George S. Eisenbarth, M.D., Ph.D., and Peter A. Gottlieb, M.D. Autoimmune Polyendocrine Syndromes. N Engl J Med. 2004; 350:
2068-79. PMid:15141045. https://doi.org/10.1056/NEJMra 030158

[5] Stefan RB. Predisposing Factors for Adrenal Insufficiency. N Engl J Med. 2009; 360: 2328-39. PMid:19474430. https ://doi .org/10 .1056/NEJMra0804635

[6] Arlt W, Allolio B. Adrenal insufficien- cy. Lancet. 2003; 361: 188193. https://doi .org/10.1016/S0140-6736(03) 13492-7

[7] Oelkers W. Adrenal insufficiency. N Engl J Med. 1996; 335: $1206-$ 12. PMid:8815944. https ://doi.org/10.1056/NEJM19961017 3351607

[8] Diabetes Prevention Trial-Type 1 Diabetes Study Group. Effects of insulin in relatives of patients with type 1 diabetes mellitus. N Engl J Med. 2002; 346: 1685-91. PMid:12037147. https: //doi.org/10.1056/NEJMoa012350 